\title{
Serum Testosterone Level as Possible Predictive Marker for Prognosis in Metastatic Castration-Resistant Prostate Cancer Patients Treated With Enzalutamide
}

\author{
Dong Hyeon An, Hwiwoo Kim, Donghyun Lee, In Gab Jeong, Dalsan You, \\ Jun Hyuk Hong, Choung-Soo Kim, Hanjong Ahn
}

Department of Urology, Asan Medical Center, University of Ulsan College of Medicine, Seoul, Korea

\begin{abstract}
Purpose: This study aimed to evaluate the impact of serum testosterone level before enzalutamide treatment in metastatic castration-resistant prostate cancer (mCRPC) for antitumor outcomes.

Materials and Methods: Single-center, retrospective study including patients that treated with enzalutamide for mCRPC before and after docetaxel chemotherapy. Clinicopathological parameters including serum testosterone at initial enzalutamide use were examined. Prostate-specific antigen (PSA) response, progression-free survival (PFS), and cancer-specific survival (CSS) were the outcomes of interest. Logistic-regression analysis was done for discovering odds for PSA response. Cox-proportional model was applied for risk stratification for progression and cancer-specific death.

Results: A total of 228 patients with mCRPC, treated with enzalutamide, both prechemotherapy and postchemotherapy, between 2011 and 2019 were included. One hundred sixty-two of patients $(71.1 \%)$ experienced PSA decline over 50\%. Median PFS and CSS were 5.4 and 13.2 months, respectively. Serum testosterone at initial enzalutamide use was the noble predictor for progression (hazard ratio [HR], $0.409 ; \mathrm{p}=0.020$ ) and cancer-specific death (HR, $0.454 ; p=0.033)$ in postchemotherapy group. No significant effect of serum testosterone in prechemotherapy group was detected. Time to CRPC, high-metastatic burden revealed as risk factors for PSA response, PFS, and CSS, both in prechemotherapy and postchemotherapy group.

Conclusions: High testosterone level at commencement of enzalutamide treatment was associated with a good prognosis in postdocetaxel setting, but not related to oncological outcomes in chemotherapy-naive patients. (Korean J Urol Oncol 2021;19:60-69)
\end{abstract}

Key Words: Prostate cancer $\cdot$ Enzalutamide $\cdot$ Testosterone

Received October 26, 2020, Revised December 15, 2020,

Accepted December 28, 2020

Corresponding Author: Hanjong Ahn

Department of Urology, Asan Medical Center, University of Ulsan College of Medicine, 88, Olympic-ro 43-gil, Songpa-gu, Seoul 05505, Korea

Email: hjahn@amc.seoul.kr

Tel: +82-2-3010-3733, Fax: +82-2-477-8928

ORCID: https://orcid.org/0000-0001-7608-5352

\section{INTRODUCTION}

Prostate cancer is one of the most commonly diagnosed cancers in men, which has 2nd most prevalence in United States and 4th most prevalence in South Korea. ${ }^{1,2}$ In metastatic disease, androgen-deprivation therapy (ADT) with or without abiraterone or docetaxel is the standard treatment on current guideline. ${ }^{3,4}$ And most of these patients experience the progression in a castration-resistant prostate cancer

(c) (i) (5) This is an Open Access article distributed under the terms of the Creative Commons Attribution Non-Commercial License (http://creativecommons.org/licenses/by-nc/4.0/) which permits unrestricted non-commercial use, distribution, and reproduction in any medium, provided the original work is properly cited. 2021 (C) Copyright The Korean Urological Oncology Society and The Korean Prostate Society. All Rights Reserved. 
(CRPC), although consecutive ADT is maintained. In treatment of metastatic CRPC (mCRPC), taxane chemotherapies, androgen receptor (AR) axis-targeting agents including enzalutamide and abiraterone, and radio-isotope radium-223 have shown survival benefits. ${ }^{5,6}$

Enzalutamide is a small-molecule inhibitor of AR which can overcome resistance to nonsteroidal antiandrogens such as bicalutamide and flutamide. Previous clinical trials with enzalutamide have consistently shown improved overall survival (OS) in CRPC, whether before or after chemotherapy. $^{5,7,8}$

Despite prostate cells in castration-resistant phase engage to survive in a low androgen environment, both residual androgen and AR play a central role to disease progression. ${ }^{9}$ In addition, prostate cancer tissues cause de novo androgen synthesis which advances the progression to CRPC, resulting in increased testosterone level in CRPC. ${ }^{10,11}$ Several attempts have been made to identify serum testosterone level as a biomarker for deciding treatment selection. ${ }^{12,13}$ Recent studies observed that serum testosterone level affected therapeutic efficacy of abiraterone and enzalutamide. ${ }^{14-16}$ However, the significance of pretreatment serum testosterone level on progression and survival in patients treated with enzalutamide for mCRPC remains limited.

Thus, the main purpose of this study is to reveal the association between serum testosterone level before enzalutamide treatment and oncologic outcomes.

\section{MATERIALS AND METHODS}

\section{Study Design}

This retrospective study based on medical records of prostate cancer patients is being reviewed by the Institutional Review Board of Asan Medical Center (S2020-2620-0001). From December 2011 to May 2019, the medical records of 266 patient who has been treated with enzalutamide for mCRPC were collected. Among these, 38 patients who treated with abiraterone before enzalutamide were excluded. At last, 228 men with mCRPC and treated with enzalutamide were enrolled. All patients were maintained androgen deprivation with added $160 \mathrm{mg}$ of enzalutamide plus prednisolone $5 \mathrm{mg}$ twice a day. The patients were divided into prechemotherapy group and postchemotherapy group.

\section{Definition}

In this study, PSA response was defined as a decrease in the level of PSA of at least $50 \%$ from initial enzalutamide use in a patient who received treatment. High-metastatic burden was defined as 4 or more bone metastasis with at least one outside the axial skeleton or presence of visceral metastases, according to the definition of CHAARTED trial. ${ }^{17}$ Grade group was defined according to the International Society of Urological Pathology consensus. ${ }^{18}$ Biochemical progression was defined as 2 serial rises in PSA level at least $\geq 25 \%$ increase and $\geq 2 \mathrm{ng} / \mathrm{mL}$ increase from baseline beyond 12 weeks. Radiographic progression was defined as 2 or more new lesion in bone scintigraphy, or visceral progression and nodal progression according to RECIST (response evaluation criteria in solid tumors).

\section{Statistical Analysis}

Clinical variables such as PSA, testosterone, grade group, metastatic burden, time to CRPC of each group and duration of taxane chemotherapy of postchemotherapy group were analyzed. PSA response, progression-free survival (PFS), and cancer-specific survival (CSS) were the interest of antitumor outcome. Differences between patient groups were analyzed using independent sample t-test for continuous variables and Fisher exact test for categorical variables. Logistic-regression analysis was used to discover odds for PSA response. Cox-proportional model was applied in order to calculate hazard ratio of clinical variables for PFS and CSS. CSS following enzalutamide initiation was calculated using Kaplan Meier estimation and log-rank test. A p-value less than 0.05 indicated statistical significance. IBM SPSS Statistics ver. 25.0 (IBM Co., Armonk, NY, USA) was used for all statistical analysis.

\section{RESULTS}

The baseline patient characteristics are summarized in Table 1. PSA and testosterone of initial enzalutamide were $171.4 \pm 419.3$ and $0.20 \pm 0.24$. PSA response, progression (biochemical, radiographic, or both), cancer-specific death was observed in 162, 158, and 130 patients. There were 136 patients of prechemotherapy group and 92 patients of postchemotherapy group. Age (76 years vs. 71 years, $p=0.004$ ), 
Table 1. Patient characteristics at initial enzalutamide use

\begin{tabular}{|c|c|c|c|c|}
\hline Characteristic & Total $(\mathrm{N}=228)$ & Prechemotherapy $(\mathrm{N}=136)$ & Postchemotherapy $(\mathrm{N}=92)$ & p-value \\
\hline Age (yr) & $74(68-79)$ & $76(70-80)$ & $71\left(66^{-77)}\right.$ & 0.004 \\
\hline PSA (ng/mL) & $38.9(11.5-136.4)$ & $33.7(10.9-126.1)$ & $47.5(12.4-170.9)$ & 0.564 \\
\hline Testosterone (ng/mL) & $0.12(0.07-0.23)$ & $0.15(0.09-0.23)$ & $0.08(0.04-0.21)$ & 0.504 \\
\hline Grade group & & & & 0.016 \\
\hline 2 & $3(1.3)$ & $1(0.7)$ & $2(2.2)$ & \\
\hline 3 & $13(5.7)$ & $12(8.9)$ & $1(1.1)$ & \\
\hline 4 & $41(18.0)$ & $29(21.3)$ & $12(13.0)$ & \\
\hline 5 & $171(75.0)$ & $94(69.1)$ & $77(83.7)$ & \\
\hline Prior local therapy & $63(25.3)$ & $43(31.6)$ & $20(21.7)$ & 0.102 \\
\hline Metastatic burden & & & & $<0.001$ \\
\hline Low & $80(35.1)$ & $62(45.6)$ & $18(19.6)$ & \\
\hline High & $148(64.9)$ & $74(54.4)$ & $74(80.4)$ & \\
\hline Bone metastasis & $198(86.8)$ & $111(81.6)$ & $87(94.6)$ & 0.005 \\
\hline Nodal metastasis & $102(44.7)$ & $58(42.6)$ & $44(47.8)$ & 0.440 \\
\hline Visceral metastasis & $32(14.0)$ & $11(8.1)$ & $21(22.8)$ & 0.002 \\
\hline Time to CRPC (mo) & $26.2(13.9-43.5)$ & $27.0(16.2-53.0)$ & $22.4(11.4-38.9)$ & 0.002 \\
\hline Duration of chemotherapy (mo) & & & $10.6(6.0-16.4)$ & \\
\hline \multicolumn{5}{|l|}{ Duration to progression } \\
\hline Overall (mo) & $5.4(2.8-10.0)$ & $6.6(3.0-11.5)$ & $4.4\left(2.6^{-7.6)}\right.$ & 0.006 \\
\hline Radiographic (mo) & $6.0(2.8-11.2)$ & $6.8(3.0-12.8)$ & $4.5(2.6-8.3)$ & 0.007 \\
\hline Cancer-specific survival (mo) & $13.2(7.08-26.0)$ & $15.8(8.0-28.8)$ & $10.7(6.4-21.1)$ & 0.014 \\
\hline PSA decline $>50 \%$ & $162(71.1)$ & $107(78.7)$ & $55(59.8)$ & 0.002 \\
\hline Cancer-specific death & $130(57.0)$ & $59(43.4)$ & $71(77.2)$ & $<0.001$ \\
\hline
\end{tabular}

Values are presented as median (interquartile range) or number (\%).

Median follow-up=10.3 months.

PSA: prostate-specific antigen, CRPC: castration-resistant prostate cancer.

number of patients of grade group $5(69.1 \%$ vs. $83.7 \%$, $\mathrm{p}=0.016)$, high-metastatic burden $(54.4 \%$ vs. $80.4 \%, \mathrm{p}<$ 0.001), time to CRPC (27 months vs. 22.4 months, $\mathrm{p}=$ $0,002)$, PSA response $(78.7 \%$ vs. $59.8 \%, p=0.002)$, cancerspecific death $(43.4 \%$ vs. $77.1 \%, \mathrm{p}<0.001)$, PFS (median: 6.6 months vs. 4.4 months, $\mathrm{p}=0.006$ ), and CSS (median: 15.8 months vs. 10.7 months, $\mathrm{p}=0.014$ ) differed significantly between patients with prechemotherapy and postchemotherapy respectively.

The results of multivariable analysis for the prediction of PSA response in enzalutamide use are shown in Table 2. In multivariable analysis, Table 2 shows that grade group 5 (odds ratio [OR], 0.430; 95\% confidence interval [CI], 0.191-0.965; $\mathrm{p}=0.041$ ), and high-metastatic burden (OR, $0.337 ; 95 \% \mathrm{CI}, 0.165-0.688 ; \mathrm{p}=0.003$ ) was the predictor of PSA response in overall population. In postchemotherapy group, high-metastatic burden (OR, 0.213; 95\% CI, 0.0540.835; $\mathrm{p}=0.027$ ) was independent factor to predict PSA response.
Cox-proportional model for progression is presented in Table 3. In overall population, age (hazards ratio [HR], 0.974; 95\% CI, 0.952-0.994; $\mathrm{p}=0.014$ ), time to CRPC (HR, 0.991; 95\% CI, 0.983-1.000; $\mathrm{p}=0.038$ ), high-metastatic burden (HR, 1.949; 95\% CI, 1.330-2.855; p=0.002) were the risk factors of progression. In prechemotherapy group, high-metastatic burden (HR, 1.787; 95\% CI, 1.058-3.020; $\mathrm{p}=0.030$ ) could predict progression. In postchemotherapy group, time to CRPC (HR, 0.985; 95\% CI 0.972-0.999; $\mathrm{p}=0.034)$ and serum testosterone level at initial enzalutamide use (HR, 0.409; 95\% CI, 0.192-0.871; $\mathrm{p}=0.020$ ) were revealed as risk factors of progression, as can be seen from Table 3.

Table 4 provides summary of Cox-proportional model for cancer-specific death. Table 4 shows that time to CRPC (HR, 0.988; 95\% CI, 0.980-0.997; p=0.008) and high-metastatic burden (HR, 2.291; 95\% CI, 1.493-3.516; $\mathrm{p}<0.001$ ) were the indicator for prediction of cancer-specific death. Same trends for cancer-specific death were found in pre 


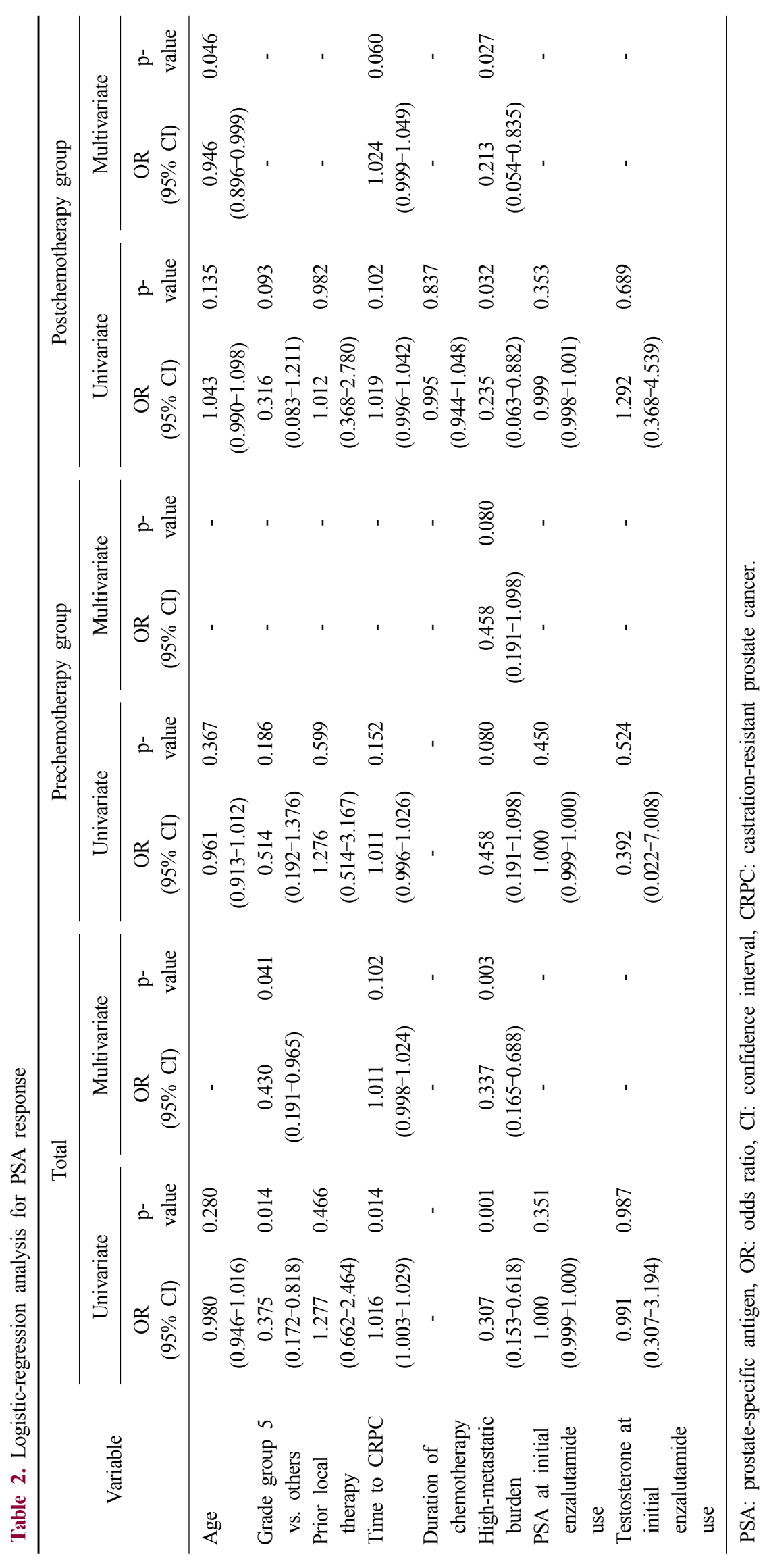




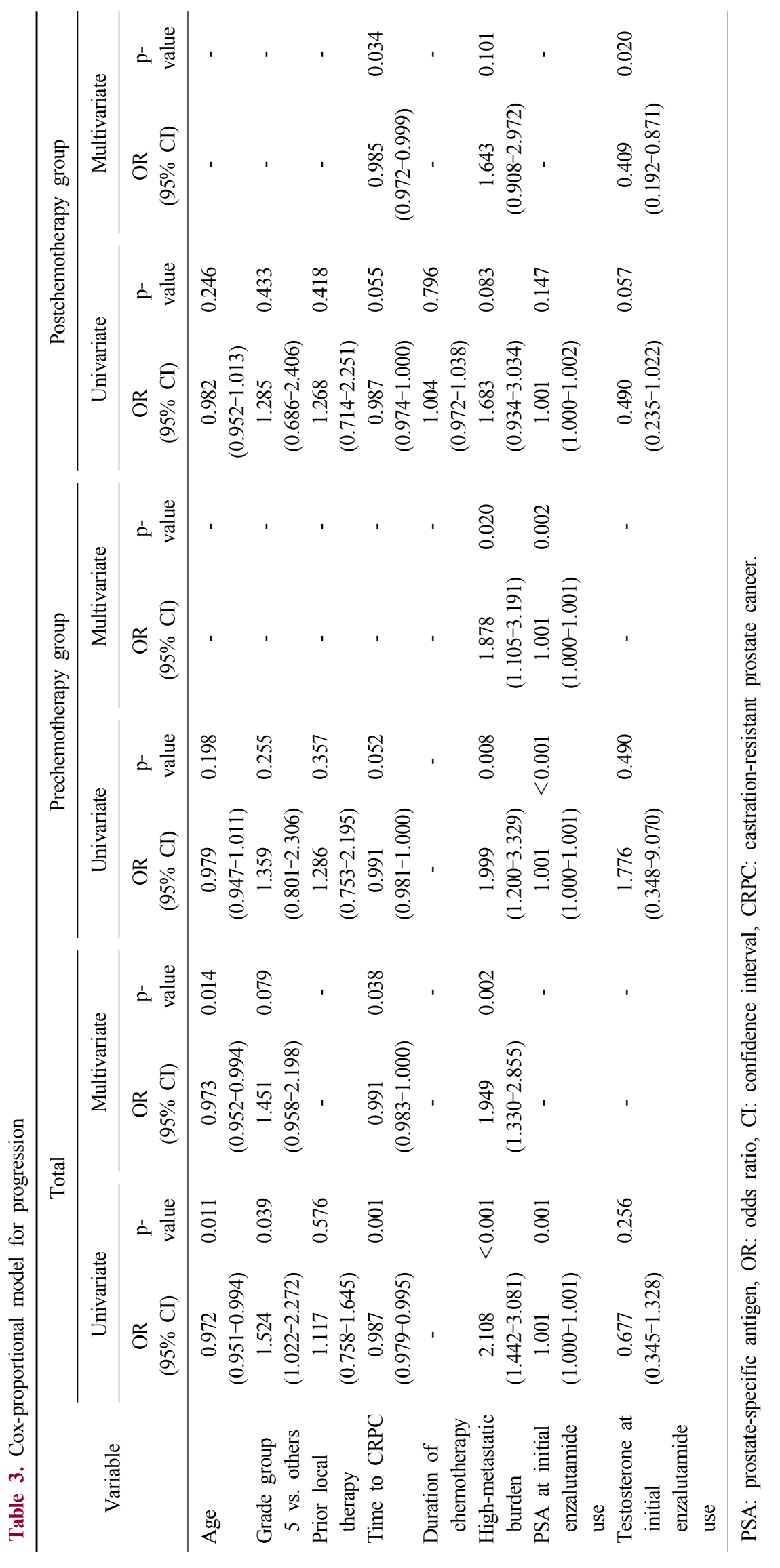




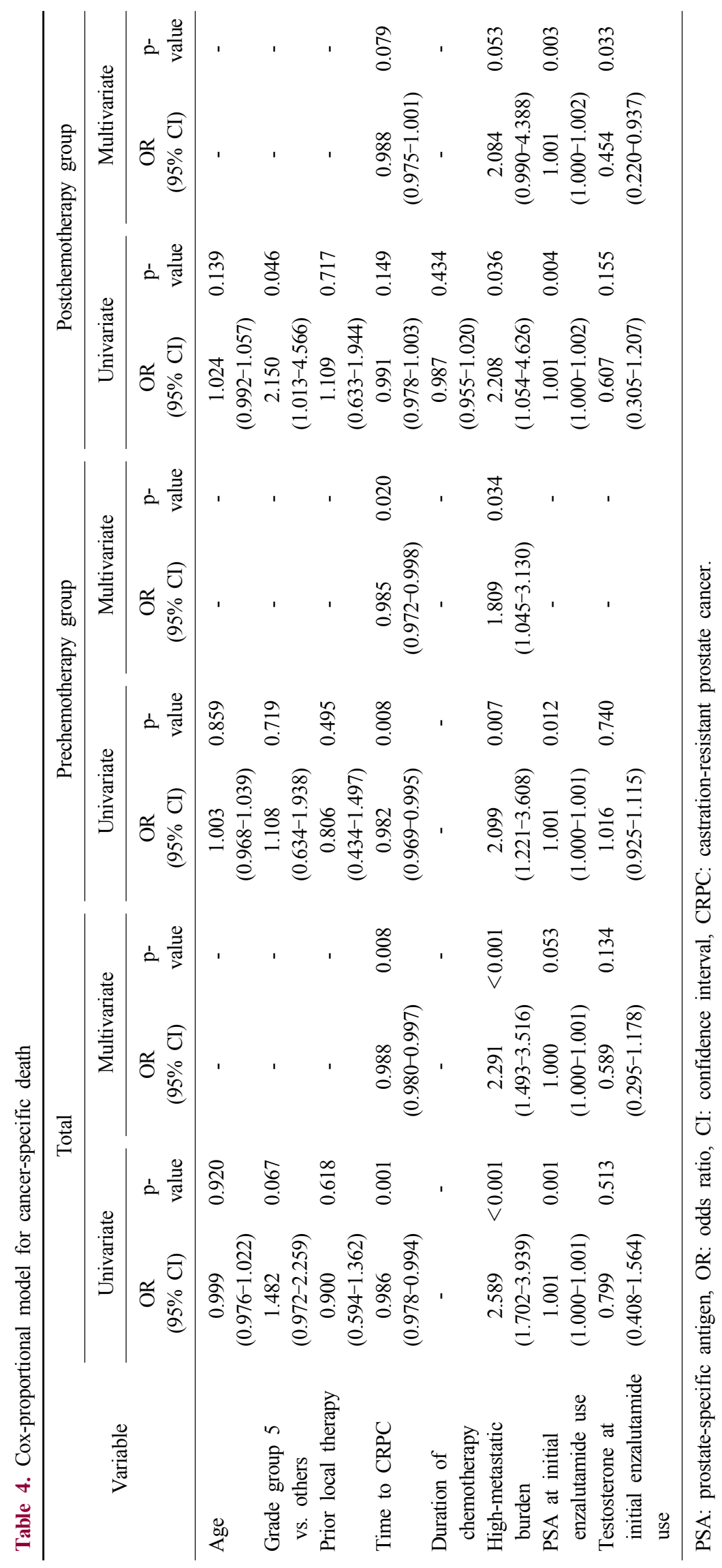


A

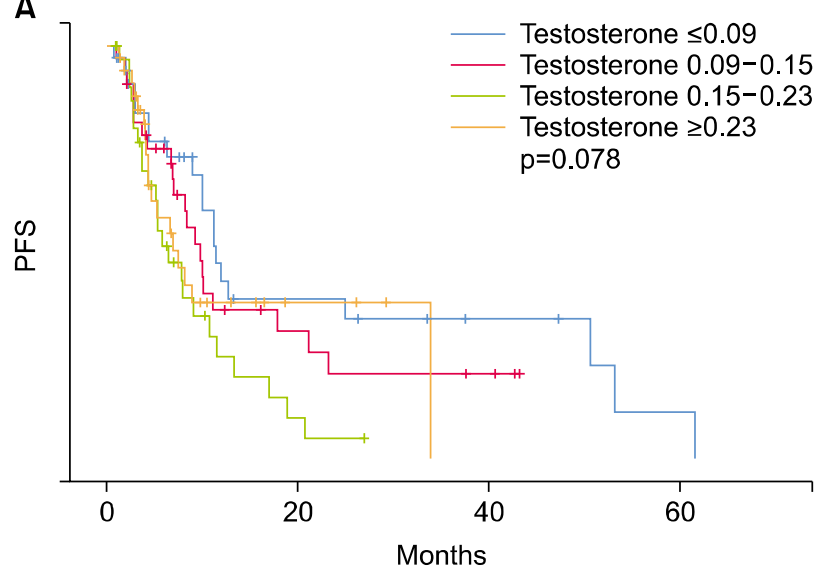

B

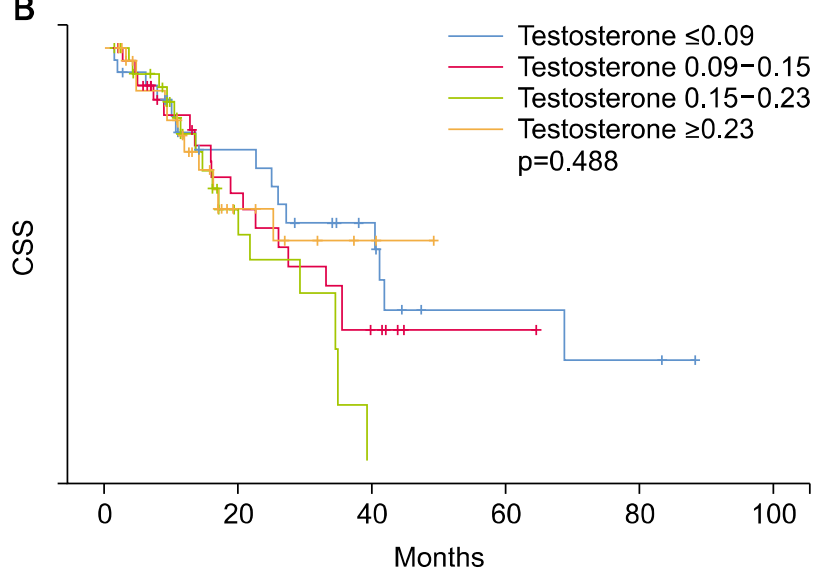

Fig. 1. Survival curve divided by the quartile of pretreatment serum testosterone levels in the prechemotherapy group. (A) Progression-free survival (PFS). (B) Cancer-specific survival (CSS).

A

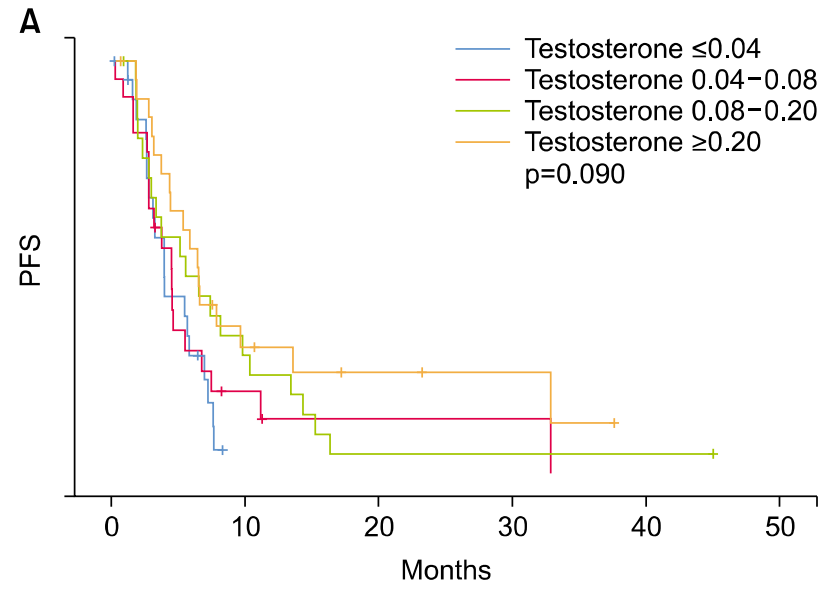

B

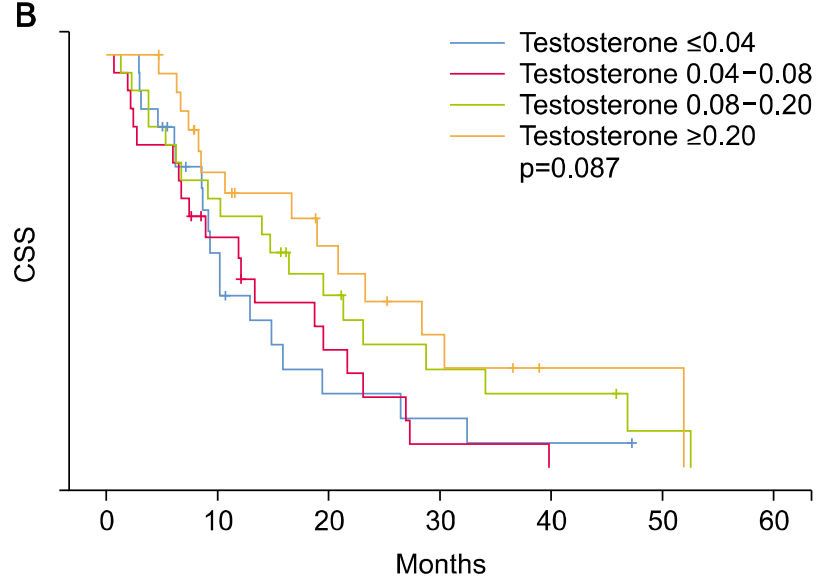

Fig. 2. Survival curve divided by the quartile of pretreatment serum testosterone levels in the prechemotherapy group. (A) Progression-free survival (PFS). (B) Cancer-specific survival (CSS).

chemotherapy group. Interestingly, serum testosterone level of initial enzalutamide use (HR, 0.454; 95\% CI, $0.220^{-}$ $0.937 ; p=0.033$ ) was the noble predictor of cancer-specific death in postchemotherapy group, as shown in Table 4.

Survival curves for each ranges of quartiles of serum testosterone level, in prechemotherapy, are shown in Fig. 1. As shown in figure, there is no statistical relationship between serum testosterone level and PFS, CSS. In postchemotherapy group, patients with serum testosterone over the median $(0.08 \mathrm{ng} / \mathrm{mL})$ has shown better PFS and OS. Survival curves for each ranges of quartiles and median of serum testosterone level are highlighted in Figs. 2 and 3.

\section{DISCUSSION}

In our analysis, PFS and CSS were better in men with higher serum testosterone level when treated with enzalutamide following docetaxel, but PSA response could not be extrapolated to high serum testosterone. In prechemotherapy setting, serum testosterone was not associated with PSA response, PFS, and CSS. This provides new insights into establishing possible biomarker for prognosis of CRPC, and biomarker for efficacy of following enzalutamide use.

An subanalysis of the COU-AA 301 trial has shown that patients with lower testosterone level in postchemotherapy treatment with abiraterone have worse OS. ${ }^{12}$ In this study, androstenedione and dehydroepiandrosterone sulfate also 
A

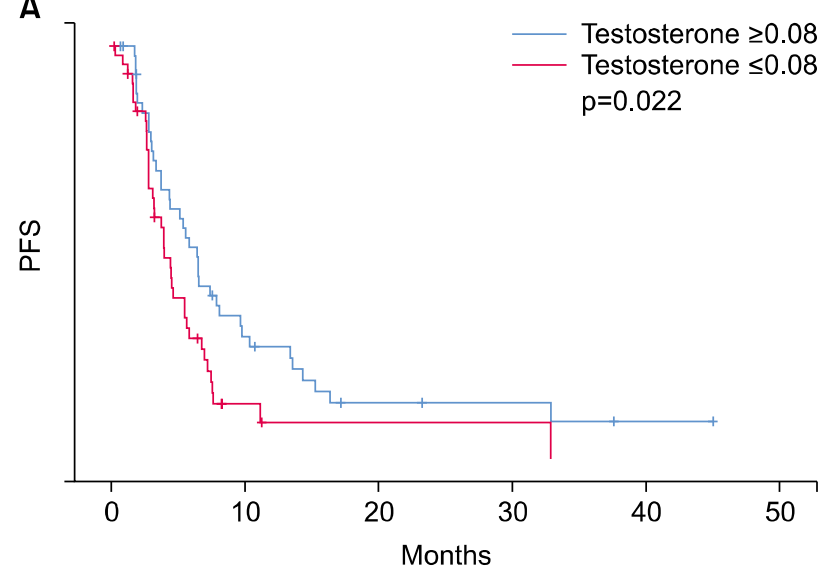

B

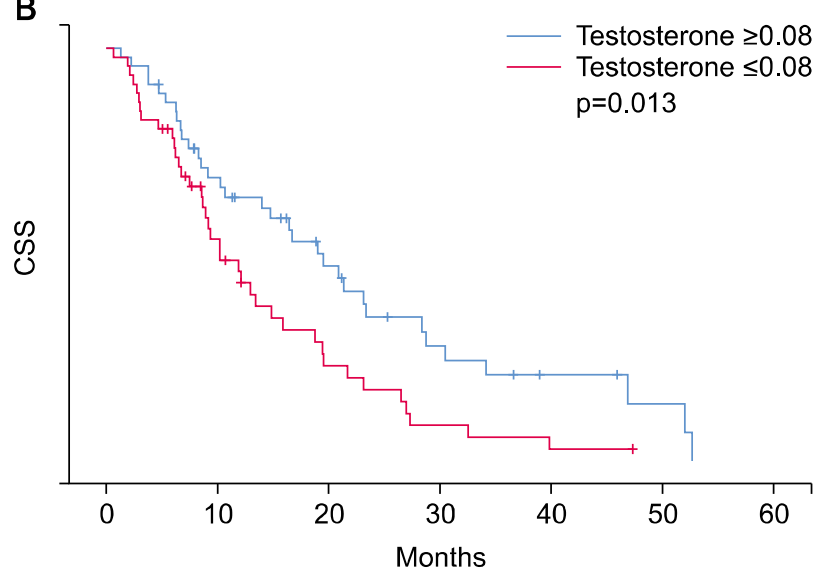

Fig. 3. Survival curve divided by the quartile of pretreatment serum testosterone levels in the postchemotherapy group. (A) Progression-free survival (PFS). (B) Cancer-specific survival (CSS).

has similar relationship was observed, in addition to testosterone. Authors explained it by the hypothesis that serum testosterone might reflect the activity of the $A R$, and tumor with amplified AR might be hypersensitive to androgens. ${ }^{19}$ And they also adverted that it needs to be interpreted cautiously, because the relationship between serum androgens and intratumoral androgens remains poorly understood.

Recent retrospective study reported that low basal testosterone level and AR copy number gain is associated with worse PFS and OS, both abiraterone and enzalutamide treatment. ${ }^{20}$ In this study, patient with testosterone below the median value experienced worse PFS and OS, with enzalutamide treatment. Also, the prognostic impact of testosterone showed better outcome in patients treated with docetaxel. Authors explained this result with mechanism of action of enzalutamide. Enzalutamide blocks the link between androgens and their receptor in prostatic cells. When serum testosterone is reduced, role of enzalutamide as an antagonist of ARs might be weakened. They also hypothesized that a progression with suppressed levels of testosterone could be more aggressive, independent of hormonal axis. Results of our investigation that higher serum testosterone is associated with better PFS and OS is supported by these studies, and we confirmed these knowledges again.

In our knowledge, no clinical trial or subanalysis of clinical trial has been conducted to analyze the effects of serum testosterone in patients using enzalutamide following docetaxel. But we know that antitumor activity of docetaxel in CRPC is represented to the prohibition of the internalization of the activated AR. Therefore, residual activity of the androgenic signal could facilitate the activity of docetaxel in limited extent. ${ }^{21}$

Previous studies had argued that patients with higher serum testosterone levels associated with favorable PFS in mCRPC patients treated with enzalutamide and abiraterone acetate. A retrospective analysis of 115 patients of CRPC treated with abiraterone and enzalutamide showed longer biochemical PFS in serum testosterone of 5-50 ng/dL group than serum testosterone of $0-5 \mathrm{ng} / \mathrm{dL}$ group. ${ }^{14}$ Another retrospective study of 107 patients treated with enzalutamide and/or abiraterone, $13 \mathrm{ng} / \mathrm{dL}$ or higher serum testosterone was correlated with PFS, and not with OS. ${ }^{15}$ The other single-center retrospective study declares that PFS among men with serum testosterone level over $0.05 \mathrm{ng} / \mathrm{mL}$ was superior to that among men with testosterone level under $0.05 \mathrm{ng} / \mathrm{mL}$ when treated with enzalutamide. ${ }^{16}$ These reports notwithstanding, our study showed contradictory results.

None of the 3 studies described above statistically demonstrated the relationship between serum testosterone levels and OS in chemotherapy-naïve patients with CRPC that treated with enzalutamide, and our research also failed. It can be assumed that the impact of serum testosterone on survival may change with secondary, tertiary, or more treatment after enzalutamide. In our cohort, of 136 patients of prechemotherapy group, 41 treated with docetaxel after enzalutamide due to progression, 17 patients treated with abiraterone following enzalutamide due to progression or ad- 
verse effect of enzalutamide. Inhibition of androgen biosynthesis (mechanisms of action of abiraterone acetate), interactions with docetaxel and subsequent treatment may alter the effects of serum testosterone on survival.

Our analysis did not derive significant association between serum testosterone level and PSA response and PFS in prechemotherapy group. Although our results are presented as continuous values of serum testosterone, the statistical results were the same when using cutoff values based on quartiles. such as $0.09 \mathrm{ng} / \mathrm{mL}$ or $0.15 \mathrm{ng} / \mathrm{mL}$. Survival curves according to quartiles of serum testosterone level did not demonstrated clear trend for PFS and CSS. This may be due to differences in the way testosterone levels are measured, or differences in patient characteristics, or poor patient randomization.

In our institution, serum testosterone level was measured with the radioimmunoassay kit (Cisbio Bioassays, Codolet, France), and the lowest testosterone level could be tested was $0.04 \mathrm{ng} / \mathrm{mL}$. In above-mentioned studies, the chemiluminescent microparticle immunoassay device (The Architect Testosterone II, Abbot Diagnostics, Lake Forest, IL, USA) was used to determine testosterone levels. So, it is possible that our device did not accurately measure the very low testosterone level which is regarded as serum testosterone $<0.05 \mathrm{ng} / \mathrm{mL}$.

The previous studies and the distribution of serum testosterone in this study also differed from previously reported results. In Japanese population, the median nadir PSA of patients treated with $\mathrm{ADT}$ is known to be $0.16 \mathrm{ng} / \mathrm{mL}$, and the mean maximum testosterone level of ADT-treated patients has been reported to be about $0.2 \mathrm{ng} / \mathrm{mL}^{22,23} \mathrm{In}$ Korean population, the mean serum testosterone level in patients who treated with Goserelin for 9 months was reported at $0.13 \mathrm{ng} / \mathrm{mL}$ recently. ${ }^{24}$ In a paper analyzing the prognosis of serum testosterone and CRPC patients published by Shiota et al., ${ }^{16}$ median pre-ART testosterone showed 0.03 $\mathrm{ng} / \mathrm{mL}$, and Sakamoto et al. ${ }^{15}$ had a median testosterone before abiraterone or enzalutamide of $0.13 \mathrm{ng} / \mathrm{mL}$. This is lower than known previously. In our data, median testosterone was $0.15 \mathrm{ng} / \mathrm{mL}$, mean serum testosterone was 0.19 $\mathrm{ng} / \mathrm{mL}(95 \% \mathrm{CI}, 0.16-0.20)$ in prechemotherapy group, which is higher than recently reported in Korea. Due to the differences in the testosterone measurement and the distribution of serum testosterone, the role of serum testoster- one in prechemotherapy group in the previous studies and this study may be different.

It is also possible that progression by other variables is masking the influence of testosterone. When chemotherapy-naïve patients were divided into 3 groups following treatment after enzalutamide $(41,17,78$ as docetaxel, abiraterone, maintaining enzalutamide or salvage ADT), there was a difference in median PSA levels between these groups $(51.1 \mathrm{ng} / \mathrm{mL}$ vs. $47.1 \mathrm{ng} / \mathrm{mL}$ vs. $21.0 \mathrm{ng} / \mathrm{mL})$. This heterogeneity might be a disturbance factor of the analysis because higher PSA level is associated with shorter interval to progression and cancer-specific death, higher rate of death in our data.

Several limitations associated with this investigation are present. First, although we have the larger number of patients compared with other studies, a small number of patients and retrospective study design may have caused a selection bias. Second, limited follow-up periods can lead to inaccurate survival analysis. Third, the timing of serum testosterone measurement was varied, and follow-up and imaging interval also does. Fourth, only testosterone level was investigated, and no androgen other than testosterone was considered. Despite of these limitations, our study may have contributed in part to the relationship between outcome of enzalutamide treatment and serum androgen level.

\section{CONCLUSIONS}

In mCRPC patients who underwent docetaxel chemotherapy, high level of serum testosterone before enzalutamide use has important implications for good prognosis, as expressed as long PFS and CSS.

\section{CONFLICT OF INTEREST}

The authors claim no conflicts of interest.

\section{REFERENCES}

1. Jung KW, Won YJ, Kong HJ, Lee ES. Cancer statistics in Korea: incidence, mortality, survival, and prevalence in 2016. Cancer Res Treat 2019;51:417-30.

2. Miller KD, Nogueira L, Mariotto AB, Rowland JH, Yabroff KR, Alfano CM, et al. Cancer treatment and survivorship statistics, 2019. CA Cancer J Clin 2019;69:363- 
85.

3. Sydes MR, Spears MR, Mason MD, Clarke NW, Dearnaley DP, de Bono JS, et al. Adding abiraterone or docetaxel to long-term hormone therapy for prostate cancer: directly randomised data from the STAMPEDE multi-arm, multi-stage platform protocol. Ann Oncol 2018;29: 1235-48.

4. Gravis G, Boher JM, Chen YH, Liu G, Fizazi K, Carducci $\mathrm{MA}$, et al. Burden of metastatic castrate naive prostate cancer patients, to identify men more likely to benefit from early docetaxel: further analyses of CHAARTED and GETUG-AFU15 studies. Eur Urol 2018;73:847-55.

5. Davis ID, Martin AJ, Stockler MR, Begbie S, Chi KN, Chowdhury S, et al. Enzalutamide with standard first-line therapy in metastatic prostate cancer. N Engl J Med 2019; 381:121-31.

6. Ryan CJ, Smith MR, de Bono JS, Molina A, Logothetis $\mathrm{CJ}$, de Souza $\mathrm{P}$, et al. Abiraterone in metastatic prostate cancer without previous chemotherapy. N Engl J Med 2013;368:138-48.

7. Beer TM, Armstrong AJ, Rathkopf DE, Loriot Y, Sternberg CN, Higano CS, et al. Enzalutamide in metastatic prostate cancer before chemotherapy. N Engl J Med 2014;371:424-33.

8. Scher HI, Fizazi K, Saad F, Taplin ME, Sternberg CN, Miller $\mathrm{K}$, et al. Increased survival with enzalutamide in prostate cancer after chemotherapy. N Engl J Med 2012; 367:1187-97.

9. Devlin HL, Mudryj M. Progression of prostate cancer: Multiple pathways to androgen independence. Cancer Lett 2009;274:177-86.

10. Mostaghel EA, Page ST, Lin DW, Fazli L, Coleman IM, True LD, et al. Intraprostatic androgens and androgenregulated gene expression persist after testosterone suppression: therapeutic implications for castration-resistant prostate cancer. Cancer Res 2007;67:5033-41.

11. Locke JA, Guns ES, Lubik AA, Adomat HH, Hendy SC, Wood CA, et al. Androgen levels increase by intratumoral de novo steroidogenesis during progression of castrationresistant prostate cancer. Cancer Res 2008;68:6407-15.

12. Ryan CJ, Molina A, Li J, Kheoh T, Small EJ, Haqq CM, et al. Serum androgens as prognostic biomarkers in castration-resistant prostate cancer: results from an analysis of a randomized phase III trial. J Clin Oncol 2013;31:2791-8.

13. Hashimoto K, Shindo T, Tabata H, Tanaka T, Hashimoto $\mathrm{J}$, Inoue R, et al. MP53-02 Serum testosterone level is a useful biomarker to aid optimal treatment selection in men with castration-resistant prostate cancer. J Urol 2017; 197(4S):e713.

14. Hashimoto K, Tabata H, Shindo T, Tanaka T, Hashimoto $\mathrm{J}$, Inoue R, et al. Serum testosterone level is a useful bio- marker for determining the optimal treatment for castration-resistant prostate cancer. Urol Oncol 2019;37:485-91.

15. Sakamoto S, Maimaiti M, Xu M, Kamada S, Yamada Y, Kitoh $\mathrm{H}$, et al. Higher serum testosterone levels associated with favorable prognosis in enzalutamide- and abirateronetreated castration-resistant prostate cancer. J Clin Med 2019; 8:489.

16. Shiota M, Kashiwagi E, Murakami T, Takeuchi A, Imada $\mathrm{K}$, Inokuchi J, et al. Serum testosterone level as possible predictive marker in androgen receptor axis-targeting agents and taxane chemotherapies for castration-resistant prostate cancer. Urol Oncol 2019;37:180.e19-180.e24.

17. Sweeney CJ, Chen YH, Carducci M, Liu G, Jarrard DF, Eisenberger $\mathrm{M}$, et al. Chemohormonal therapy in metastatic hormone-sensitive prostate cancer. N Engl J Med 2015;373:737-46.

18. Egevad L, Delahunt B, Srigley JR, Samaratunga H. International Society of Urological Pathology (ISUP) grading of prostate cancer - an ISUP consensus on contemporary grading. APMIS 2016;124:433-5.

19. Friedlander TW, Roy R, Tomlins SA, Ngo VT, Kobayashi $\mathrm{Y}$, Azameera A, et al. Common structural and epigenetic changes in the genome of castration-resistant prostate cancer. Cancer Res 2012;72:616-25.

20. Lolli C, De Lisi D, Conteduca V, Gurioli G, Scarpi E, Schepisi G, et al. Testosterone levels and androgen receptor copy number variations in castration-resistant prostate cancer treated with abiraterone or enzalutamide. Prostate 2019;79:1211-20.

21. Darshan MS, Loftus MS, Thadani-Mulero M, Levy BP, Escuin D, Zhou XK, et al. Taxane-induced blockade to nuclear accumulation of the androgen receptor predicts clinical responses in metastatic prostate cancer. Cancer Res 2011;71:6019-29.

22. Takei A, Sakamoto S, Wakai K, Tamura T, Imamura Y, $\mathrm{Xu} \mathrm{M}$, et al. Duration of androgen deprivation therapy and nadir of testosterone at $20 \mathrm{ng} / \mathrm{dL}$ predict testosterone recovery to supracastrate level in prostate cancer patients who received external beam radiotherapy. Int J Urol 2018; 25:352-8.

23. Fujii Y, Yonese J, Kawakami S, Yamamoto S, Okubo Y, Fukui I. Equivalent and sufficient effects of leuprolide acetate and goserelin acetate to suppress serum testosterone levels in patients with prostate cancer. BJU Int 2008;101: 1096-100.

24. Shim M, Bang WJ, Oh CY, Lee YS, Cho JS. Effectiveness of three different luteinizing hormone-releasing hormone agonists in the chemical castration of patients with prostate cancer: goserelin versus triptorelin versus leuprolide. Investig Clin Urol 2019;60:244-50. 